\title{
Las pasiones y la razón de vivir
}

\section{Paulina Rivero}

Remo Bodei, Geometría de las pasiones. Miedo, esperanza, felicidad: filosofia y uso político. Trad. de Isidro Rosas. México, FCE, 1995, 490 pp.

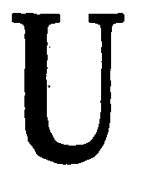

na pregunta gravita en esta obra de Bodei: ¿qué tan cercanos estamos hoy en día al peor de los pecados: la ausencia de pasiones? En el mundo contemporáneo cada vez se reduce más el ámbito de las pasiones; la indiferencia recíproca y el individualismo de masa, que termina en el rechazo al contacto directo y en la completa separación de los otros, conlleva al inevitable marchitamiento emotivo y la desaparición de la solidaridad. Esta es entendida por Bodei como el sentimiento que puede llevarnos a compartir la pasión del otro, a compartir su pathos: la com-pasión y sim-patía, en el sentido griego de la palabra, no se refieren a otra cosa que a esa posibilidad de compartir la pasión: sentir como propio lo que al otro le pasa, vivir lo que el otro vive, sufrir lo que el otro sufre, de manera que el pathos del otro, no sea ajeno; la solidaridad es lo contrario de la in-dolencia, que es la imposibilidad de sentir el dolor del orro.

¿Pero cómo sentir la pasión del otro cuando el ritmo de vida cotidiano y la estructura de la convivencia social se caracterizan por la obstrucción de las pasiones? Y a la vez: ¿Cómo podemos hablar de obstrucción de pasiones, en un mundo que al menos en apariencia es conducido por relaciones de mercadotecnia que se basan en la creación artificial de deseos? Toda la publicidad, en las calles, en las tiendas, "enganchan" al consumidor creando deseos en él. Para Remo Bodei, el hecho de que el impulso adquisitivo haya tomado vigor hasta hacerse tan familiar, es algo a lo que no se le ha dedicado la atención necesaria. Este autor analiza algunos fenómenos que han sido provocados en la vida cotidiana por una economía orientada al consumo. Demuestra cómo la supuesta "democratización" en el trato al consumidor

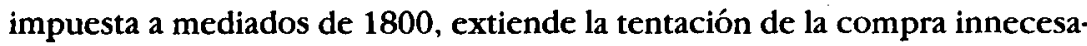
ria a todo posible consumidor. El deseo de adquirir más y más, la pleonexia, o ansia insaciable de posesión, que antaño era el pecado de pecados, se ha convertido en nuestro pan diario. 
La intención de Remo Bodei es hacernos ver cómo todo esto ha incidido en un cambio, en una reorientación de las pasiones. Pareciera ser que las pasiones ceden su espacio a los deseos, y ni siquiera se trata ya de satisfacer un deseo sino de multiplicar los deseos, que Bodei define como "pasiones de espera dirigidas a bienes o a satisfacciones imaginadas en el futuro". Pero estos deseos que se afirman como fantasías de satisfacción individual, son realmente insituables. No miran a la satisfacción en sí, ni de impulsos ni de necesidades, sino a aspiraciones de una felicidad malentendida como un cumplimiento impostergable de deseos, deseos que a la vez se insertan en la perspectiva del futuro. El deseo se conserva como ansia de ver lo que aún no es presente, como algo que depende de la carencia o ausencia del objeto, que nos remite a la dimensión de las esperanzas actualizables.

Habria hoy en día una hipertrofia de los deseos, y una atrofia de las pasiones. Las pasiones, con su carácter de apego al objeto, ceden lugar a los deseos inquietos, cambiantes, cercanos a los sueños e incapaces de cristalizarse. Estos deseos, que de por si dependen de la incertidumbre del futuro, adquieren ritmos vertiginosos logrando individuos con una gran versatilidad en la restauración de la propia identidad. Ante este panorama, el libro de Bodei pretende enfocar los problemas relacionados con las pasiones y trazar una linea interpretativa plausible elaborando soluciones relativas al estatuto de las pasiones, los deseos y su tratamiento en la esfera ética y política.

Remo Bodei, catedrático de historia de la filosofia en la Escuela Normal de Pisa, filósofo inicialmente conocido como hegeliano a través de su libro Sistema y época en Hegel, a lo largo de su obra se ha preocupado -y ocupado- de problemas relativos al hombre moderno y la posibilidad de su felicidad. La Geometría de las pasiones es una obra que puede ser leída con gusto. Insertada en la misma línea de pensamiento marcada por el filósofo Baruch Spinoza, Bodei concibe su labor similar a la de las abejas, que elaboran y dan sabor a lo que han recolectado, y no a la de las hormigas que sólo recolectan para acumular, ni al trabajo de las "arañas-genio" que secretan autárquicamente las propias idas de su boca. En ese sentido el libro entrelaza historia y teoría, se remonta a la tradición homérica, pasando por Platón, Aristóteles, Séneca, Pascal, Descartes, Spinoza, Hobbes, y los jacobinos franceses, e incluso llega a retomar algunas ideas fundamentales sobre las pasiones expuestas en el pensamiento de Schopenhauer, Nietzsche, Marx, Freud, y muchos autores más. Pero su análisis no se limita al área de la filosofia, son también abundantes y oportunas las citas y los ejemplos tomados de estudios históricos y de obras literarias.

En ninguno de los casos se queda en la mera exposición de ideas: Bodei pretende ir más allá, en busca de una ética que no vuelva rígidos sus principios y reglas, pero que tampoco retroceda detrás de las líneas de la 
racionalidad, una ética en la cual las pasiones sean comprendidas como formas expresivas y refinadas, y no como meros impulsos primitivos $e$ inmutables.

La gran presencia a lo largo de toda la obra de Bodei es Spinoza. Para ambos, el hecho de que por mucho tiempo las pasiones hayan sido condenadas como factor de turbación o de pérdida temporal de la razón, no implica que no podamos hacer filosofía sobre ellas, hablar sobre ellas y dar razón de ellas. Pero no sólo "podemos" filosofar sobre ellas, es necesario denunciar el uso político que se ha hecho de las pasiones, particularmente, en el caso de Bodei, el uso político que se ha hecho del miedo y la esperanza.

El miedo y la esperanza, para Bodei, son pasiones que bloquean el potenciamiento del individuo hacia estados de mayor perfección. En términos políticos oponerse al miedo es rechazar el absolutismo y la razón de Estado, y oponerse a la esperanza es golpear en el centro mismo del corazón de la religión. Liberado del miedo y de la esperanza puede el individuo llevar a cabo todas sus potencialidades, elaborando sus pasiones y su razón. Aquel que se libera del miedo y la esperanza puede llegar a cumplir la máxima aristotélica: conviértete en quien eres; la alegría y la beatitud son para aquellos que han triunfado sobre el miedo a la muerte y sobre su supuesto remedio que es la esperanza. Pero no se trata de combatir a las pasiones para quedarse con un mundo puramente racional. Esto equivaldría a continuar viendo en las pasiones el signo de podercs cxtraños para "la parte mejor del hombre", que lo dominan distorsionando la clara visión de las cosas y desviando la espontánea propensión al bien. Esa concepción de las pasiones presupone en el scr humano energias salvajes que deberian ser dirigidas y frenadas por una instancia ordenadora iluminada: la "razón". Con este esquema es fácil prefigurar una justificación polémica para reprimir las pasiones, por considerarlas incapaces de guiarse a sí mismas, negándoles así una orientación intrínseca y legitimando a la razón en sus intervenciones de censura y de tutela correctiva.

Remo Bodei pretende una ética que permanezca en el ámbito de la dualidad entre razón y pasión, para lo cual considera necesario abandonar la imagen de la relación pasión razón como arena de la lucha entre lógica y ausencia de lógica, entre orden y desorden, transparencia y oscuridad, ley y arbitrio, en fin: entre unidad monolítica de la razón y pluralidad desintegral de las pasiones.

Es necesaria, una revaloración de las pasiones y una comprensión de su lógica. Ellas no se reducen a conflicto y pasividad: tiñen el mundo de colores, acompañan el desarrollo de los acontecimientos, sacuden la experiencia de la inercia y la monotonía, dan sabor a la existencia a pesar de las incomodidades y los dolores. ¿Valdría la pena vivir si no probásemos alguna pasión, 
si tenaces e invisibles hilos no nos atasen con fuerza a cuanto nos llega al corazón y cuya pérdida tememos? La total apatía, la falta de sentimientos y de re-sentimientos, la incapacidad de alegrarse y de entristecerse, de estar llenos de amor, odio, deseo o cólera, la misma desaparición de la pasividad, entendida como espacio virtual y acogedor para la presentación del otro, ¿no equivaldría tal vez a la muerte? La ausencia de pasiones, y no la pasión misma, sería entonces el verdadero pecado.

En su estructura el libro esta concebido geométricamente como una elipse, diseñada de vez en vez como parejas de focos que son los puntos de irradiación y condensación de problemas. Son los dos núcleos generadores de los cuales se origina el análisis respecto a las pasiones y virtudes: el miedo y la esperanza. Para Remo Bodei estas dos pasiones permiten un acceso privilegiado a la comprensión de problemas filosóficos y políticos fundamentales. Aparecen como un obstáculo para quien pretende su autodominio y, al mismo tiempo, ofrecen instrumentos eficaces de control y de dominio a quien gobierna a otros. La esperanza -exaltada por el pensamiento utópico y cristiano- es comprendida por Bodei "como un simple aspecto del miedo", y desde esta perspectiva se propone una ética desvinculada tanto del miedo como de la esperanza.

Todas estas ideas son analizadas como focos de una elipse, el primero de los cuales es Spinoza. Se analiza la política como el gobiemo de las pasiones, y la progresiva transición de las pasiones a los afectos, que serian pasiones privadas ya de su elemento de pasividad, vueltas inteligibles e inteligentes por medio de su comprensión adecuada, en lugar de su tratamiento represivo. Spinoza es ubicado en su combate ante dos frentes: Hobbes y su interpretación del miedo a la muerte y, por otro lado, los "apóstoles de la esperanza". Ante los regímenes que se fundan en el miedo y la esperanza, que disminuyen la capacidad de autocontrol y racionalidad y aumentan la superstición y la pasividad, la democracia aparece como una posibilidad de favorecer el desarrollo de la racionalidad en la conducta de los ciudadanos. En ella la razón es la palanca o punto de apoyo que eleva las pasiones a afectos.

Lo que resulta inaceptable, tanto para Spinoza como para Bodei, es pedir el sacrificio de los individuos o de sus pasiones en nombre del Estado o de Dios. La autoconservación se robustece en la alegría, en la sociabilidad y el amor intelectual del Dios spinociano. De esta manera para Bodei, Spinoza representa un puente que media entre las éticas del autocontrol -y de la manipulación política de las pasiones-y las que dejan abierto el campo a la inconmesurabilidad del deseo. Y por ello Spinoza contribuye a derribar el muro que tradicionalmente divide a las pasiones de la razón, y a la inquietud masiva de la serenidad del sabio. 
El segundo foco de la elipse lo encontramos en el análisis de las prácticas teóricas del jacobinismo francés y por el uso del miedo y la esperanza. El miedo se vuelve terror y la esperanza se dirige a la regeneración de la humanidad futura. El manejo del miedo y de la esperanza del jacobinismo no resulta hoy en día algo lejano, para Bodei es de hecho casi un arquetipo de los modernos movimientos políticos de emancipación. Las viejas esperanzas del "hombre nuevo" o de la "nueva sociedad" continúan caracterizando este siglo que está por cerrarse, en el cual seguimos presenciando el florecimiento de grandes esperanzas colectivas y la difusión de inenarrables miedos.

Spinoza y los jacobinos representan dos polos opuestos ante el miedo y la esperanza. Los segundos no pretenden eliminar miedo o esperanza, sino consolidarlos. Bodei reconstruye estas dos posiciones a lo largo de la historia, y las confronta con algunas posiciones éticas contemporáneas. Finalmente Bodei retoma la idea spinociana de "amor intelectual" como la razón reforzada por pasiones emancipadoras: la lógica spinociana del amor intelectual se contrapone tanto a la de las pasiones como a la de la pura razón. El amor intelectual no se refiere al ámbito emotivo, sino más bien a una estructura que a la vez es emotivo-cognitiva, conocimiento que mueve, movimiento que conoce. De ahi que el amor intelectual sea capaz de desbloquear conflictos mediante soluciones innovadoras que incrementen la racionalidad sin mutilar el deseo. Es factible, pues, hablar del pathos de la razón, del fuego en la mente humana. Esta idea del amor, de honda tradición filosófica, desmiente la concepción de las pasiones como monstruos surgidos de energias incontrolables, y permite concebir al ser humano como una unidad dual de razones y pasiones, más que como el campo de una batalla interminable.

Sin embargo, llama la atención que las ideas de Bodei, que pretenden encaminarse hacia una ética nueva y son prefiguradas con nitidez en la introducción que el autor escribe para su obra, no terminan de explicitarse a lo largo de la misma. Sin lugar a dudas los conocimientos del autor sobre el tema son vastos y sólidos: como lo hemos dicho, el análisis filosófico, literario e histórico están presentes a lo largo de toda la obra, al igual que el análisis político llevado a cabo a partir de la Revolución francesa. Pero no profundiza en las premisas y los fundamentos de esa ética que él mismo pretende haber plasmado en esta obra, lo cual hace que queden en el aire ciertos temas enunciados como fundamentales en el inicio de la misma. Así, aquel fenómeno del creciente "impulso adquisitivo" -que había sido denunciado en el principio del libro como "algo a lo que aún no se ha prestado la atención que merece" - y la idea de que ese fenómeno ha incidido hoy en día en una reorientación de las pasiones hacia la creación y multiplicación de los deseos, son ideas que no vuelven a ser retomadas ni analizadas en el libro. En ese sentido podriamos decir que este libro de Bodei, más que expo- 
ner una nueva ética, "se dirige a" o "señala hacia" una ética que conjunte pasiones y razones más allá del miedo y la esperanza.

Por último, sólo quiero reflexionar qué tan factible puede ser pretender una ética más allá de la esperanza. Cierto que la falsa esperanza ha sido y sigue siendo utilizada como un instrumento de dominio, que concentra la energía de las personas en la espera de que la miseria termine y el mundo cambie en un futuro terrenal o celestial. Pero ello no implica que toda esperanza sea falsa: tal vez podría distinguirse entre una falsa esperanza, y una esperanza racional, terrena, inmanente: esperamos no morir al minuto siguiente, por lo cual tenemos un proyecto de vida, esperamos lograr nuestro crecimiento y para ello trabajamos. La esperanza que nos activa, que nos hace seres activos -y no pasivos- que nos hace pensar, es la esperanza de ese Sísifo feliz que es el ser humano. Y esa esperanza racional puede ser también fuego en la mente humana, puede ser el pathos de la razón que implica el rescate de los dos mundos que algún día Kant declarara inconciliables, y que antes Spinoza se propusiera conciliar: la razón y la pasión. 